\title{
Xenotransplantation: Perspectives and Limits
}

\author{
Claus Hammer \\ Institute for Surgical Research, Ludwig Maximilians University Munich, Germany
}

\section{Key Words}

Xenotransplantation • Limits · Immunology • Virology •

Species specificity $\cdot$ Ethics

\begin{abstract}
Xenotransplantation faces the dilemma of an unlimited supply of cells, tissues and organs on the one hand and severe obstacles and limits on the other. One reason for the limitations is that the source animal of choice, the pig, and the human recipient separated 90 million years ago during evolution, a time in which biological characteristics such as anatomy, physiology and immunology have had much time to drift far apart. The acceptance of such an evolutionary widely divergent organ, especially the heart of a pig, could evoke refusal of xenotransplantation in conservative and religious patients. New legal aspects of allocation of xenografts have therefore to be reflected upon and appropriate guidelines developed. Inquiries show, however, that the acceptance of all types of porcine organs would be high if the quality of life after receiving such a xenograft is comparable to that after
\end{abstract}

Presented at the 18th Annual Meeting of the International Society of Blood Purification, Rome, September 7-9, 2000. receiving the same allograft. This individual benefit of a xenograft could lead to a disregard of the collective risk in terms of xenozoonoses, often presented as a catastrophic scenarium. Therefore, transplantation societies and ethics committees have published comments and even guidelines for handling future clinical xenotransplantation. All three monotheistic religions and Hinduism support the idea of saving and improving human life with the help of an animal organ.

Copyright $@ 2001$ S. Karger AG, Basel

The worldwide lack of organs for transplantation forces scientists to search for new alternatives to solve this problem in the near future. Xenotransplantation with its unlimited sources opens new perspectives to improve this situation in the next decades. Yet, the last 30 years of investigation have added many new aspects to the initially purely immunological approach. Fields like anatomy, physiology and virology have been discovered to be crucial for the long-term survival of a xenograft and the patient. Ethical, religious, legal and financial problems have to be discussed in the interest of the public, especially in our multicultural societies.

Thus, xenotransplantation faces the dilemma of excellent perspectives on the one hand and severe limits on the other.

\begin{tabular}{ll}
\hline KARGER & ( ) 2001 S. Karger AG, Basel \\
0253-5068/01/0193-0322\$17.50/0 \\
$\begin{array}{l}\text { Fax +4161306 12 34 } \\
\begin{array}{l}\text { E-Mail karger@karger.ch } \\
\text { www.karger.com }\end{array}\end{array}$ & $\begin{array}{l}\text { Accessible online at: } \\
\text { www.karger.com/journals/bpu }\end{array}$
\end{tabular}

Prof. Dr. C. Hammer

Institute Surgical Research, Klinikum der Universität München

Marchioninistrasse 15

D-81 377 Munich (Germany)

Tel. +49897095 4402, Fax +49897095 8897, E-Mail hammer@icf.med.uni-muenchen.de 


\section{Choice of Source Animals}

Selection of a suitable xenograft for clinical xenotransplantation strongly depends on the phylogeneic relationship between the species of the source animal and man. Experimental settings clearly indicate that survival times of xenografts are inversely proportional to the evolutionary time and/or phylogeneic distance [1].

Transplants between individuals of one zoological family, i.e. between zoologically closely related animals like mouse and rat or man and ape reach survival times similar to those achieved in allogeneic combinations. The rejection mechanism is dominated by cellular interactions and can be mitigated by conventional immunosuppression.

The genetic relationship of species is based on the similarity of the structural and organizational development of the DNA. In reassociation experiments and DNA-DNA hybridization, it was shown that $98 \%$ of human DNA can be found in the genes of chimpanzees, $92 \%$ in baboons and $85 \%$ in cynomolgus monkeys.

The major histocompatibility locus (MHC) of primates has been highly conserved throughout the vertebrate evolution. A large part is similar to that of man. Mixed lymphocyte reactions show responses in man and chimpanzee comparable to those in allogeneic combinations. Tissue typing of chimpanzee and baboon was tried successfully with sera used for human typing.

Enzymes analogous for man possess the same substrate specificity in most old-world monkeys. Hemoglobins remain similar if not identical, and most blood group antigens are comparable and can be tested with the human tools. All primates, in contrast to most other mammals, induce isoantibodies. Preformed natural antibodies beside the (preformed) isoagglutinins are not found between chimpanzee and man. These data show that primates and especially chimpanzees would be the ideal source of organs for man in terms of histocompatibility. This was proven in one of the first clinical xenotransplantations reported by Reemtsma et al. [2]. But several mayor obstacles prohibit the use of nonhuman primates as organ source. Almost all infectious diseases are transferable from primates to man. All primates are rare and because they reproduce slowly are endangered species. In addition, it is morally not acceptable to use animal species facing extinction only to treat a few lethally ill, maybe old-age patients. The production of chimpanzees to a number needed today for transplantation would last approximately 100 years, that of baboons 70 years. Prospects which not only limit but exclude this possibility of transplantation on a large scale [3].
The optimal animal species for clinical xenotransplantation should be of a size similar to that of the recipient human being and available in reasonable numbers. It should be easy to handle and cheap in terms of production and care. These demands can only be fulfilled by domestic animals, particularly by the domestic pig.

The disadvantage of this species widely divergent from man, a discordant combination, is that most characteristics compatible in the primate combination are incompatible between pig and man. The DNA association is less than $70 \%$. The 15 blood groups found in pigs belong to the salivatory type, like the Rhesus factor, and like major histocompatibility antigens, they are completely different from the human type. Isoagglutinins do not exist. The mean titer of preformed natural antibodies against human epitopes is one of the highest in the class of mammals.

Enzymes and hormones differ in almost all cases in over $30 \%$ of the amino acid sequences. This means that no interaction with the human receptors, transmitters, carrier molecules and inhibitors can be expected. In addition, molecules with an amino acid sequence of less than $80 \%$ identity are antigenic and induce antibodies.

For xenotransplantation, these limitations, developed by evolution during the last 180 million years, have to be outwitted before clinical application of pig organs can start [1].

\section{Transgenic Manipulation of Pigs}

In order to prolong the survival time of xenografts from pigs and to inhibit the mechanisms of the xenogeneic hyperacute rejection, transgenic technology was introduced [4]. The carefully directed inhibition of the complement cascade by introducing the human decay accelerating factor (h-DAF) gene into the porcine genome has resulted in a significant inhibition of the xenogeneic hyperacute rejection process. The inhibition of both the $\mathrm{C} 3$ and $\mathrm{C} 5$ convertase blocks the second half of the complement cascade, but has no impact on the first part of the classical pathway [5]. The introduction of multiple complement regulator genes, in form of a minichromosome with 3 genes (h-DAF, MCP, CD59), did not add much to the results of h-DAF only [6].

Other transgenic manipulations like inactivation of the $1,3 \mathrm{Gal}$-transferase gene by homologous recombination until today showed only a marginal effect. Transgenic expression of the FAS-ligand or TRAIL was even less successful, inducing enhancement of rejection. Transgenic 
modulation of the blood-clotting cascade is in progress [7].

The question arises, how many human genes have to be introduced in the pig genome until an optimal compatible porcine 'strain' has been created suitable for xenotransplantation. The limit of this technique is not in sight, but the exchange or knockout of all genes characterizing porcine incompatible characteristics does not seem to be feasible in the near future. Pigs justifying cloning for clinical purposes do not yet exist.

The most intriguing problem seems to be the unpredictable and irregular side effects of genetic interferences. Some of the gene constructs induce multiple changes including lethal ones [8]. The induction of one human characteristic promoter is not enough if the human inhibitor is lacking. In the case of the human growth hormone, the unlimited increase in the foreign organ leads to giant porcine kidneys or hearts, a situation not compatible with human life [9].

\section{Capacity of Organs}

The applicability of different organs and tissues has not been sufficiently investigated. Surgical procedures known from allotransplantation have governed the use of primary vascularized organs. Little is known about xenogeneic tissue like bone, skin and cartilage. Corneas, islets, thyroids and parathyroids have been taken into consideration. Transplantation of bone marrow has even be tried in a desperate clinical situation [10].

The results depend heavily on antigenicity and speciesspecific function of the grafts. From preliminary results, it can be assumed that simple organs and tissues are better feasible than organs and tissues composed of many different cell types and products. Islets from the pig seem, judging by the overall physiological aspect, to be the most compatible porcine graft, with heart, kidney and liver situated at the far end.

The porcine liver, producing a myriad of incompatible molecules, will hardly be equal to the tremendous task of being a substitute for a human organ for any length of time. Such chaotic disregulations can lead to deadly misfunctions in an anyhow lethally ill patient.

If the basic disease is the aim of the treatment, one could imagine that a few isolated pure hepatocytes, for example, might be able to produce or replace one lacking compatible molecule. $\alpha_{1}$-Antitrypsin is one such molecule which, if deficient, leads to an end-stage liver disease in children and could be replaced. The species-specific and thus incompatible function of a whole liver, however, is too multifactorial to be tolerated. Bioreactors could be an alternative to fill the gap of such a disorder. There exists an enthusiastic approach concerning the healing of diseases by xenografts. But even slight discrepancies of action might lead to major metabolic problems. This is known even from several autologous genetic disorders in which only one molecule, hormone or enzyme did not function physiologically, leading to severe malfunction. Complete cure of a complex disease by the use of xenografts remains to be proven. In other words, there exist excellent, good, bad and impossible applications of xenografts.

\section{Preformed Natural Antibodies}

Preformed natural antibodies (PNAb) initiate the classical pathway of the complement cascade by activating the endothelial cell layer of blood vessels. Recent work has proven that galactosyl epitopes, particularly the Gal 1,3 $\mathrm{Gal}$, are the main targets of PNAbs on the surface of the endothelial cells. Yet, less than $10 \%$ of the immunoglobulins are directed against these antigens [11]. Many other types of antispecies antibodies are supposed.

Various types of elimination procedures for these PNBAbs exist. Plasmapheresis with columns coated with sheep antihuman IG absorb most efficiently almost all the $\gamma$-globulins, a situation beneficial in experimental approaches, but not useful in life-long treatment. Within a short time, the antibodies reappeared, often showing a rebound effect [12].

Selective absorption of the anti-1,3 Gal antibodies on specific columns is expensive and did not achieve the success expected. Too many additional antibody types and classes are left over, and are also able to induce the rejection mechanism [13]. Immunosuppression and genetic manipulation has had only a marginal impact on these preformed antibodies [14-16].

The reappearance of secondary specific antibodies, now mainly of IgG types, is another limitation for longterm survival of xenogeneic organs. These antibodies act in minute amounts and are highly specific. The present immunosuppression seems to be inefficient. These secondary antibodies will not allow a retransplantation of an organ from the same species. 


\section{Viral Transfer and Infection}

All mammals are hosts of various types of germs. Most of them are species specific and not able to contaminate individuals of other zoological background.

A limited number of infections can be transferred from one species to another under normal contact. They are called zoonoses. If transmitted by a xenograft, the disease is called xenozoonosis. No such disease has been reported to date. In vitro, various human primary cells and immortalized cell lines have been infected with porcine endogen retroviruses (PERV) [17]. This liberation of C-type viruses able to infect immortalized human cells was, however, regarded as a possible cell culture artifact. Using these methods, 3 types of PERVs can be distinguished [18]. This finding has evoked severe concern, and several scientists, especially virologists, have asked for a moratorium on xenotransplantation.

Due to the intensified search for viruses other than PERV, several new viruses have been detected in pigs and are under investigation for their contagious potential for man. Since most of these studies do not reflect a clinical situation, it remains unclear whether PERVs will be transferred together with a xenograft [19].

The fear that high immunosuppression together with transgenic manipulations could increase the possibility of transfection is not verified. One hundred and sixty patients who had received vital porcine tissue or organs as transplants were investigated for PERV contamination or immunological reaction against the xenogeneic virus. No signs of PERV infection or antibodies against PERV were found. This is also true for a number of patients with terminal liver disease who were treated by ex vivo perfusion of h-DAF transgenic porcine livers as a bridge. After allogeneic liver transplantation and normal immunosuppression, no signs of PERV contamination could be proven either [20]. It is, however, of ethical importance whether individual benefit should have the advantage over collective risk. It has to be emphasized, that without clinical perspectives in the field of xenotransplantation, the investigation of porcine viruses and germs would not have received this amount of interest.

\section{Physiological Function}

Physiological characteristics change from species to species. Common attributes like cell division, membrane structure and intermediate metabolism indicate the close relationship between man and the other mammals. Other basic metabolic characteristics like $\mathrm{pH}$, urine production and osmolarity, blood pressure, temperature regulation and oxygen uptake in relation to body size are almost identical in all mammals [21]. But many other characteristics are so different between species that cooperation, interaction, integration and maintenance of organ function are impossible.

Some beneficial developments have been conserved by nature over millions of years, like for example calcitonin and insulin in pig and man; others change within a zoological family, like tumor necrosis factor $\beta$ in primates.

Some of the molecules have, despite a similar amino acid sequence, a completely different function in other species. However, messenger molecules must be compatible with the carrier molecules and the receptors. Fastreacting mediators must have similar fast-reacting counterparts. The levels of circulating soluble molecules must match with the number of receptor structures on the target cell surface. There exist myriads of variations which can disturb the humoral concert and therefore nullify the action of the xenograft.

From this point of view, the physiological discrepancies could, after intensive investigation, represent the most serious limitation, but no systematic investigation in this direction exists [22].

\section{Blood Groups}

The blood groups of animals are extensively studied in the domestic races [23]. Usually they are of salivatory type and resemble the human rhesus system. Isoagglutinins are common in primates, but rare in other species. Therefore, no primary reaction occurs after the first allogeneic and even xenogeneic blood transfusion. Preformed natural antibodies, however, react in any case when porcine red blood cells (RBCs) are incubated in human serum. The $\alpha$-Gal epitope has been identified as one major antigen also on RBCs. Removal of anti- $\alpha-\mathrm{Gal}$ antibodies alone from the human serum, however, is insufficient to circumvent antibody-independent immune responses. In pigs of different races blood group systems $\mathrm{A}-\mathrm{N}$ have been described [23]. Only the porcine blood group A-O was found to have similarities with the human ABO system. Absorptions of anti- $\alpha-\mathrm{Gal}$ antibodies prove that antinon- $\alpha-G a l$ antibodies bind specifically to antigens on pig RBCs.

In addition, pigs possess the SLA system on white blood cells and platelets. The gene frequencies of this system are only partly differentiated. They will also inevita- 
bly play a role in xenotransplantation and represent another obstacle [23].

Respiratory pigments like hemo- and myoglobin differ significantly between pig and man. The structure is related to the binding capacity of oxygen. The changes of the $\alpha$ - and $\beta$-chain deriving from common ancestors differ in the degree of mutational steps. Only in closely related species is hemoglobin similar if not identical [24].

The idea of heterologous blood transfusion is not yet seen as a future clinical approach. The use of xenogeneic hemoglobins as oxygen carriers is, however, under investigation [25].

\section{Blood Viscosity}

There exist little data about blood viscosity in various animals. Blood viscosity differs significantly, due to the differences in hematocrit of $42 \%$ in man and $30 \%$ in the pig. Viscosity depends on the quality of the various blood components, including total protein and the number and size of the blood cells. Viscosity expressed as Pascal/second is $5.9 \mathrm{~Pa} / \mathrm{s}$ in the pig as compared to $4.7 \mathrm{~Pa} / \mathrm{s}$ in man. This might be due to the flexibility of RBCs, the tendency to aggregate and the concentration of fibrinogen. Shear rate and temperature have an impact on viscosity too. Immunosuppression, which depresses the production of all blood components, decreases hematocrit and thus viscosity. Because of the higher viscosity in man, a reduced hemoperfusion of pig organs has to be expected, which would be especially critical for coronary blood flow [26].

\section{Blood-Clotting System}

Vascularized porcine xenografts overexpressing hDAF are still lost within weeks by acute vascular rejection, vascular-based inflammation, thrombo- and leukopenia and disseminated intravascular coagulation. These complications develop despite apheresis of preformed antibodies and despite inhibition of the complement cascade. In other words, xenogeneic blood clotting occurs independently from immunological mechanisms.

Quiescent endothelial cells express effective anticoagulant mechanisms that maintain microcirculatory homeostasis and vascular integrity under physiological conditions. Activation of endothelial cells within an ultrashort time lead to a loss of these molecules on the cell surface, and in addition start intracellular mechanisms which lead to the expression of molecules which activate the bloodclotting cascade [27].

It is not known whether incompatible mechanisms are inoperative or block the clotting cascade, or enhance only parts of it, leading in any case to a chaos as soon as extreme anticoagulation by heparin or hirudin is tapered off.

Molecular incompatibilities of coagulation factors can already be detected in monkeys leading to thrombotic microangiopathy as shown in the few cases of clinical xenotransplantations [28].

In the porcine system, the tissue factor pathway and, more importantly, the inhibitors (TFPI), the thrombomodulin and the von Willebrand factor are very different. Porcine TFPI in contrast to human TFPI is not able to inhibit human factor $\mathrm{X}$ activation. Porcine EC induce higher TF and ICAM-1 expression on human monocytes compared to human EC. Human prothrombin and factor $\mathrm{X}$ are activated by human EC. First trials to manipulate these redundant mechanisms are started in mice. However, achieving a similar expression in pigs faces many limitations.

Since porcine thrombomodulin does not bind human thrombin, human protein $\mathrm{C}$ is able to generate thrombin, which, by itself, is responsible for the cessation of microcirculation in xenogeneic primate organs [29]. Together with the enhanced von Willebrand factor, this incompatible interaction will be a major obstacle and limitation for long-term xenotransplantation.

\section{Microcirculation}

The mechanisms described are initiating reactions which act on the multiple phenomena made visible by histology or more recently by intravital microscopy. Thrombin initiates clotting and aggregation of thrombocytes in parallel to the expression of selectins, integrins and adhesion molecules. In detail, h-DAF acts on the second half of the complement cascade, while $\mathrm{C} 1-\mathrm{C} 4$ are not inhibited. $\mathrm{C} 1 \mathrm{q}$ results in the activation of the platelet fibrinogen receptor GPIIa/IIIb with the expression of $\mathrm{P}$ selectin on thrombocytes. But $\mathrm{P}$ selectin also promotes the plateletleukocyte interaction and thus the monocyte tissue factor. This can be demonstrated by the immediate loss of platelets and leukocytes in the perfusing xenogeneic blood even in transgenic models, after the apheresis of preformed antibodies, splenectomy or heavy immunosuppression with cyclophosphamide [30]. 


\section{Economics of Xenotransplantation}

Financing xenotransplantation is a perspective which has been realized only recently [31]. If xenotransplantation becomes a reality, more than ten times the number of today's transplantations could be performed. Pharmaceutical companies have invested large amounts of money hoping for a reward in the not too distant future. Since xenografts are declared as drugs in some countries, they can be sold. Estimations about the costs of production of clinically applicable perfectly 'clean' transgenic porcine grafts indicate that in the beginning xenotransplantation is more expensive than allotransplantation [32].

Kidney transplantation would save costs in the following years as compared to dialysis if the organs work long and immunosuppression is cheap. However, unlimited numbers of hearts and livers will save many patients who cannot necessarily go back to work, and will need financial support either from the governments or health insurances.

Even if xenotransplantation is used for elective transplantation, the precautions like viral tests, preservation of tissues, isolation or quarantine of the patient and high immunosuppression will increase the expenditure over that of allotransplantation.

\section{Ethics and Xenotransplantation}

Ethical problems of xenotransplantation are much more complex than those of allotransplantation. The use of animal organs is accepted in all Western countries; however, the acceptance by the recipient is significantly more multiform than that of a human graft [33]. The patient's autonomy, the conflicts of the relatives and the dignity of the patient must be taken into consideration by the surgeon even after the permission of the general and local ethics committee. We have to take into account the professional ethics and the medical ethos. There could be a hasty decision in a desperate situation. The aspects of international reputation and career might play a role.

We have to respect the global impact, the cultural and the religious situation of our multicultural countries. A careless surgeon could initiate political and legal controversies.

In fact, these limitations were realized for the first time in medical history before the actual operation, the clinical xenotransplantation, had even started. Many committees have been called to develop guidelines which prevent possible turmoils about xenotransplantation [34].

A hasty and inconsiderate moratorium of this new and promising therapy would, however, be contraproductive, and would not only stop the scientific interest and enthusiasm, but also the financial support of this extremely fruitful field of research - xenobiology.

\section{References}

1 Hammer C: Nature's obstacles to xenotransplantation. Transplant Rev 1994;8:174-184.

2 Reemtsma K, McCracken B, Schlegel J, Pearl M, Pearce C, DeWitt C, Smith P, Hewitt R, Flinner R, Chreech O: Renal heterotransplantation in man. Ann Surg 1964;160:384-405.

3 Goodal J: Ethical concerns in the use of animals as donors; in Hardy M (ed): Xenograft 25. Amsterdam Elsevier, 1989, pp 335-358.

4 White D, Langford E, Cozzi E, Young V: Production of pigs transgenic for human DAF. A strategy for xenotransplantation. Xenotransplantation 1995;2:213-218.

5 Dalmasso A, Vercellotti C, Platt J, Bach F: Inhibition of complement-mediated endothelial cell cytotoxicity by decay-accelerating factor. Potential for prevention of xenograft hyperacute rejection. Transplantation 1991;52: 530-533.

6 Carrington C, Richards A, Cozzi E, Langford G, Yannoutsos N, White D: Expression of human DAF and MCP and on pig endothelial cells protects from human complement. Transplant Proc 1995;27:321-322.
7 Robson S, Kopp C: Disordered thromboregulation in discordant xenograft rejection. Life Sci 1996;6:34-38

8 Wanke R, Herrmanns W, Folger S, Brem G: Accelerated growth and visceral lesions in transgenic mice expressing foreign genes of the growth hormone family. A review. Mol Biol Med 1991;5:513-521.

9 Soin B, Ostlie D, Cozzi E, Smith K, Bradley J, Vial C, Masroor S, Lancaster R, White D, Friend P: Growth of porcine kidneys in their native and xenograft environment. Xenotransplantation 2000;7:96-100.

10 Exner B, Neipp M, Ilstad S: Baboon bone marrow transplantation in humans: Application of cross-species disease resistance. World J Surg 1997;21:962-967.

11 Galili U, Gregory C, Morris R: Contribution of anti-Gal to primate and human IgG binding to porcine endothelial cells. Transplantation 1995;60:210-213.
12 Brenner P, Reichenspurner H, Schmoeckel M, Wimmer C, Meiser B, Hammer C, Reichart B: IG-Therasorb immunoapheresis in orthotopic xenotransplantation of baboon with landrace pig hearts. Transplantation 2000:69:208-214.

13 Lin L, Birch P, Davis R, Diamond L, Logan J, Platt J: The role of natural anti-Gal xenotransplants. Transplant Immunol 1997;5:212-218.

14 Blakely M, Van-der-Werf W, Dalmasso A, Bach F: Anti-B-cell agents: Suppression of natural antibodies and prolongation of survival in discordant xenografts. Transplant Proc 1994; 26:1374-1375.

15 Latinne D, Soares M, Havaux X, Cormont F, Bach F, Bazin H: Depletion of IgM natural antibodies by injection of anti-m $\mu$-monoclonal antibodies. Immunol Rev 1994;141:95-125.

16 Ohdan H, Yang Y, Sykes M: Reduction of antiGal alpha 1-3 Gal natural antibodies in sera of alpha 1,3 Gal GT-transferase deficient mice receiving Gal-positive bone marrow transplantation. Transplant Proc 199;31:945-946. 
17 Patience C, Takeuchi Y, Weiss R: Infection of human cells by an endogenous retrovirus of pigs. Nat Med 1997;3:282-288.

18 Paradis K, Langford G, Long Z: Search for cross-species transmission of porcine endogenous retrovirus in patients with living pig tissue. Science 1999;285:1236-1240.

19 Tonjes R, Lower R, Boller K, Denner J, Hasenmaier B, Kirsch H, Kurth R, Herv-K: The biological most active human endogenous retrovirus family. J Acquir Immune Defic Syndr Hum Retrovirol 1996;13(suppl 1):S261-S267.

20 Luo Y, Ding J, Nagappan K, Levy G, Grant D Transgenic h-DAF pig livers perfused ex-vivo with human blood have superior function and no evidence of hyperacute rejection compared to wild type livers. 5th Congress on Xenotransplantation, Nagoya, 1999, Abstract 0117.

21 Kirkman R: Of swine and man: Organ physiology in different species; in Hardy M (ed): Xenograft 25. Amsterdam, Excerpta Medica, 1989, pp 125-129.

22 Hammer C: Physiological obstacles after xenotransplantation. Ann NY Acad Sci 1998;862: 19-27.
23 Schmid D, Buschman H: Blutgruppen bei Tieren. Stuttgart, Enke, 1985.

24 Barnabas J, Goodman M, Moore G: Evolution of hemoglobins in primates and other therian mammals. Comp Biochem Physiol 1970;39: 455-482.

25 Standl T, Horn P, Wilhelm S, Greim C, Jacobs $\mathrm{E}$, Esch $\mathrm{J}$ : Bovine hemoglobin is more potent than autologous red blood cells in restoring muscular tissue oxygenation after profound hemodilution in dogs. Can J Anaesthesia 1996; 43:714-723.

26 Seehofer D, Baatz H, Thiery J, Hammer C: Quantitative analysis of the microcirculation of xenogeneic perfused rat livers by intravital microscopy. Transplant Int 1999;9(suppl 1): 97-99.

27 Robson S, Young V, Cook N, Metternich R, Kaspar-König W, Lesnikiski B: Thrombin inhibition in an ex-vivo model of porcine heart xenograft rejection. Transplantation 1996;61: 862-868.

28 Starzl T, Fung J, Tzakis A, Todo S, Demetris A, Marino I, Zeevi A, Michaelis M: Baboon-tohuman liver transplantation. Lancet 1993;341: $65-71$
29 Kopp C, Siegel J, Hancock W, Anrather J, Winkler H, Geczy C, Back F: Effect of porcine tissue factor pathway inhibitor on human coagulation factors. Transplantation 1997;63:749_ 758.

30 Diefenbeck M, Linke R, Seehofer D, Terajima $\mathrm{H}$, Thiery J, Hammer C: Intravital microscopic investigation of xenogeneic microcirculation and impact of complement depletion by cobra venom factor. Xenotransplantation 1999;5: 262-273.

31 Gonwa T: Transplantation. Am J Kidney Dis 2000;35:153-159.

32 Squinto S: Xenogeneic organ transplantation. Curr Opin Biotechnol 1996;7:641-645.

33 Schlitt H, Brukhorst R, Haverich A, Raab R: Attitude of patients towards transplantation of xenogeneic organs. Langenbecks Arch Surg 1999;384:384-391.

34 Hammer C, Molloy B: Ethical aspects of xenotransplantation. Transplant Proc 1993;24:3840. 